\title{
The role of radiotherapy in the treatment of tumours in children
}

\author{
DOROTHY PEARSON \\ From the Christie Hospital and Holt Radium Institute, Manchester
}

SYNOPSIS Radiotherapy has an established place in the treatment of some tumours in children, both for cure and palliation. An evaluation of this form of treatment is made, based on experience with the children admitted to the Christie Hospital and Holt Radium Institute during the past 30 years.

To-day radiotherapy is accepted as one of the major weapons against malignant disease, but for most radiotherapists the experience which can be gained in treating tumours in children is limited by the fact that children form a very small part of normal radiotherapeutic practice. In addition the tumours which occur in children are quite different from those seen in adults, a fact illustrated in Table $I$, which gives the relative incidence of the tumours in children and adults in a year's practice in a radiotherapy centre. These two facts make it impossible and also undesirable for the radiotherapist to base the treatment of children purely on experience with adults.

\section{TABLE I}

MAIN TYPES OF MALIGNANT TUMOURS IN CHILDREN AND ADULTS SEEN AT THE CHRISTIE HOSPITAL AND HOLT RADIUM INSTITUTE IN 1953

\begin{tabular}{lcc} 
Distribution by Sites & $\begin{array}{c}\text { Percentage } \\
\text { in Children }\end{array}$ & $\begin{array}{c}\text { Percentage } \\
\text { in Adults }\end{array}$ \\
\hline Lymphatic and haemopoietic tissue & $22 \cdot 9$ & $4 \cdot 3$ \\
Brain and cord & $20 \cdot 8$ & $0 \cdot 6$ \\
Abdomen & $25 \cdot 0$ & $3 \cdot 0$ \\
Connective tissue and bone & $12 \cdot 5$ & $1 \cdot 5$ \\
Orbit & $8 \cdot 3$ & $0 \cdot 1$ \\
Skin & 0 & $25 \cdot 4$ \\
Breast & 0 & $25 \cdot 4$ \\
Uterus & 0 & $11 \cdot 0$ \\
Mouth and lip & 0 & 6.4
\end{tabular}

Over the past 25 to 30 years valuable data have been gained in the response of both children and their tumours to radiation therapy, so that it is now possible to make an evaluation of the role of radiotherapy in the treatment of tumours in children, particularly in the more commonly occurring types. Table II shows the part that various forms of treatment have played in the surviving patients included in the Manchester Children's Tumour Register in nine years. The conclusions in this paper regarding the role of radiotherapy will be based not
TABLE II

TREATMENT GIVEN TO 285 CHILDREN NOW ALIVE AND WELL BETWEEN SEPTEMBER 1953 AND SEPTEMBER 1962

\begin{tabular}{lr} 
Treatment & No. of Cases \\
\hline Excision alone & 162 \\
Radiotherapy with or without surgery & 96 \\
Radiotherapy plus chemotherapy with or without surgery & 10 \\
Chemotherapy alone & 8 \\
Biopsy & 3 \\
No treatment & 6 \\
Total & 285
\end{tabular}

only on these cases but also on a larger number of children treated at the Christie Hospital and Holt Radium Institute during the past $\mathbf{3 0}$ years.

The first group of tumours to be considered comprises those of the nervous system, which accounts for practically one third of all tumours seen in children. The majority of these arise in the brain or spinal cord, and in Table III it can be seen

\section{TABLE III}

FIVE-YEAR RESULTS OF TREATMENT OF TUMOURS OF THE CENTRAL NERVOUS SYSTEM (1931-57)

\begin{tabular}{|c|c|c|}
\hline Type of Tumour & No. Treated & $\begin{array}{l}\text { Five-year } \\
\text { Survival }(\%)\end{array}$ \\
\hline $\begin{array}{l}\text { Medulloblastoma } \\
\text { Astrocytoma of cerebellum }\end{array}$ & $\begin{array}{l}50 \\
17\end{array}$ & $\begin{array}{l}38 \\
59\end{array}$ \\
\hline Other infratentorial tumours & $\begin{array}{l}32 \\
\text { Not histologically } \\
\text { proved } 24 \\
\begin{array}{l}\text { Histologically } \\
\text { proved } 8\end{array}\end{array}$ & $\begin{array}{l}28 \\
\text { Not histologically } \\
\text { proved } 36 \\
\text { Histologically } \\
\text { proved } 0\end{array}$ \\
\hline Supratentorial & 28 & 21 \\
\hline $\begin{array}{l}\text { Miscellaneous } \\
\text { Meningioma } \\
\text { Fourth ventricle ependymoma } \\
\text { Leptomeningeal sarcoma } \\
\text { Spinal cord }\end{array}$ & $\begin{array}{r}4 \\
\mathrm{a} 4 \\
2 \\
12\end{array}$ & $\begin{array}{r}75 \\
0 \\
0 \\
25\end{array}$ \\
\hline Total & 149 & 35 \\
\hline
\end{tabular}


that $35 \%$ of cases of all tumours of the central nervous system survive five years. The breakdown of this group is of some interest, although with small numbers of cases, statistical stability is not possible.

Cerebellar medulloblastomas form the largest group of central nervous system tumours in children. Because these neoplasms can metastasize throughout the cerebrospinal pathway, they are incurable by surgery alone. The fact that they are highly radiosensitive has made it possible to devise a technique whereby the whole central nervous system is treated in one volume, using a moderate dose of $x$ rays. Thirty-eight per cent of the patients treated in this way have survived five years. Unfortunately late recurrence, even as long as $\mathbf{1 2}$ years after treatment, can happen.

Astrocytoma of the cerebellum is of course a relatively benign tumour but has a significant mortality. In many instances, this tumour can be eradicated by the neurosurgeon, and in many cases in the Children's Tumour Register cure by surgery alone has been possible. There remain, however, those cases in which residue is present or recurrence takes place, and these cases have been treated by radiation to the posterior fossa. In the Christie Hospital series $x$-ray treatment of such cases has resulted in a five-year survival rate of $59 \%$.

The other tumours which occur below the tentorium are mainly those of the brain-stem. In these cases a biopsy is contraindicated, and therefore treatment has to be given without histological proof. In the few cases where sections were available these were obtained at necropsy. $X$-ray treatment to the brain-stem is limited by the danger of damage to normal tissues, but within these limits there has been a survival rate of $28 \%$.

Tumours arising above the tentorium in the cerebral hemispheres are relatively uncommon, with a variety of histological diagnoses. In our series 34 patients had cerebral lesions and the histological types are shown in Table IV. Techniques of treatment have been variable but of all cases $21 \%$ have survived five years, most of the survivors being from the more differentiated group of tumours.

Other tumours arising in the brain have been seen

TABLE IV

SUPRATENTORIAL TUMOURS

\begin{tabular}{lc} 
Type & No. of Cases \\
\hline Glioblastoma & 10 \\
Astrocytoma & 6 \\
Ependymoma & 3 \\
Oligodendroglioma & 1 \\
Teratoma & 2 \\
Craniopharyngioma & 1 \\
No pathology & 11 \\
Total cases & 34
\end{tabular}

in such small numbers that it is imposssible to draw any conclusions.

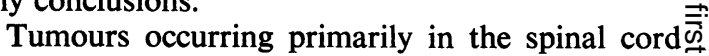
have also been of a variety of histological types, as? shown in Table $\mathrm{V}$. The results of treatment are not significant.

TABLE V

SPINAL CORD TUMOURS

\begin{tabular}{|c|c|}
\hline \multicolumn{2}{|c|}{ SPINAL CORD TUMOURS } \\
\hline Type & No. of Cases \\
\hline Astrocytoma & 5 \\
\hline Ependymoma & 5 \\
\hline Sarcoma & 2 \\
\hline Fibroblastoma & 1 \\
\hline Total cases & 15 \\
\hline
\end{tabular}

Outside the central nervous system there are two 은 neural tumours which are of interest to the radio- $\vec{c}$ therapist. Retinoblastoma can be cured by removal of the affected eye provided the tumour is confined to the globe. In bilateral cases this would of course $\%$ lead to total blindness, and therefore radiation? techniques have been perfected which will cure the tumour and at the same time preserve sight. Success in the radiotherapy of these intraocular growths depends really on the fact that the disease is usually considerably more advanced in one eye than in the $\stackrel{\square}{\square}$ other and this permits the less affected eye to be $\vec{F}$ saved. Stallard (1955) has described his particular 3 technique and the excellent results he has obtainedin both survival and preservation of sight. Althougho radiotherapy has proved of great value in the treatment of retinoblastoma which is confined to the? eye, the outlook for children with extraocular 3 spread is much worse. Although $x$-ray treatment is always tried in these late cases it is likely that veryo few patients can be saved once the growth has spread outside the globe.

The neuroblastoma may originate in the supra $\frac{D}{0}$ renal gland or anywhere along the sympathetic chain Unfortunately more cases present with metastases 0 either in bone or liver than with a single primary tumour. The increase in urinary excretion of catecholamines now helps to establish the diagnosis and to assess the effects of therapy. Treatment of most of these patients can unfortunately only be palliative, but in those cases where no distan metastases are present, surgical removal followed by $x$-ray therapy does have some success, especially in patients under the age of 1 year. It is this group of younger children which leads to the overall surviva $\underset{\mathbb{P}}{\mathrm{P}}$ figures of approximately $20 \%$.

The other main abdominal tumour in children is the nephroblastoma or Wilms's tumour of thes kidney. It is a comparatively rare tumour and in the 
Manchester region there are about six cases per year. The treatment of nephroblastoma should be a combination of surgery and radiotherapy. In our series radiation is given to the whole abdomen, with shielding of the other kidney and femoral epiphyses. Depending on the size and operability of the tumour, $x$-ray treatment is given either before or after nephrectomy. Those having surgery first were mainly children with smaller and earlier tumours while pre-operative irradiation was reserved for more advanced cases. The three-year survival rates for the whole group and the different treatment policies are shown in Table VI. The cases having $x$-ray therapy alone were so advanced or metastatic that they never became fit enough for nephrectomy to be performed.

\section{TABLE VI}

RESULTS BY METHOD OF TREATMENT IN WILMS'S TUMOURS 1940-60

\begin{tabular}{lccc} 
Treatment & $\begin{array}{l}\text { Number } \\
\text { Treated }\end{array}$ & $\begin{array}{l}\text { Three-year } \\
\text { Survivors }\end{array}$ & $\begin{array}{c}\text { Percentag } \\
\text { Survival }\end{array}$ \\
\hline $\begin{array}{l}\text { Post-nephrectomy } \\
\text { radiotherapy }\end{array}$ & 46 & 22 & $47 \cdot 4$ \\
$\begin{array}{l}\text { Pre-nephrectomy } \\
\text { radiotherapy }\end{array}$ & 29 & 7 & $24 \cdot 1$ \\
Radiotherapy only & 21 & 0 & 0 \\
All methods & 93 & 29 & $30 \cdot 2$
\end{tabular}

The lungs are the most common sites of metastases from the nephroblastoma and whilst with most malignancies little is gained from treating pulmonary secondaries, a survival rate of $14 \%$ has been achieved in children with nephroblastoma which had spread to the lungs.

Ewing's tumour of bone has been a debatable tumour, some pathologists maintaining that these are all metastatic neuroblastoma. To the clinician it certainly presents as a primary malignant tumour of bone, very unlike the usual picture of neuroblastoma. In the cases we would clinically label Ewing's tumour we have not detected any raised urinary catecholamines. This tumour is sensitive to $x$-ray treatment, but metastasis is the rule and very few survivors are seen; in fact, of all the patients included in the Tumour Register only one has survived for over five years.

The remaining tumours which occur in children are only rarely seen by the radiotherapist. Because of this it is still not possible to say what the results of treatment with radiotherapy are likely to be. Connective tissue sarcomata are not as uncommon as Wilms's tumour, but in the majority of instances are treated by surgery, and where this is possible it should be the treatment of choice. Radiotherapy should, however, always be considered in inoperable cases, as connective tissue tumours may sometimes be radiosensitive if they occur in children, whereas they would be resistant in adults. This is particularly the case in the rhabdomyosarcoma arising in the orbit, where treatment of recurrences has produced a number of cures.

The reticulo-endothelial neoplasms such as Hodgkin's disease are treated in children in just the same way as in adults, and since they present no special problems: will not be considered in any more detail.

With the advent of more efficient chemotherapy the treatment of children with acute leukaemia does not often come into the realm of the radiotherapist, except as a palliative treatment for some specific unpleasant symptoms. Two which come to mind are the relief of superior vena caval obstruction from enlarged mediastinal lymph nodes and intracranial symptoms due to leukaemic deposits, when intrathecal methotrexate has been unsuccessful. This illustrates the other role of radiotherapy in the treatment of children with tumours, i.e., as palliation to relieve symptoms which are either distressing to the child or its parents. Into this group falls the simple $x$-ray treatment to relieve bone pain or proptosis in metastatic neuroblastoma.

In treating malignant disease with radiation, the doses which have to be employed are bound to result in some damage to normal tissues with immediate and later sequelae. The immediate effects include skin reactions (usually to-day not severe), epilation when the scalp has to be treated, and reduction in the white cell count in the peripheral blood when large volumes are treated. These reactions, except in very small babies, are in no way greater than those experienced in adults.

In recent years it has been realized that the kidney is relatively sensitive to $x$ rays, and in retrospect it is obvious that in some of the earlier cases the kidney received a higher dose than it could tolerate and thereby suffered acute damage, with fatal consequences. This is now avoidable and care is taken to keep the dose to the kidney well below its tolerance. Due to the fact that the normal tissues in children are more actively growing than in adults, the later effects of radiation are more obvious. The two which are most apparent are the effect on bone growth, seen in the shortened trunk where radiation has been given to all or part of the spine, and the possible ovarian effects in girls who have had the lower abdomen treated. In five girls who have been irradiated in this region and reached the age at which the menarche is to be expected, two have shown apparently normal development with menstruation, two have developed normal secondary 
sex characteristics but have not menstruated, and one has failed to develop completely.

Unfortunately many children treated for tumours of the central nervous system are left with residual defects, including blindness and mental retardation. It is possible that in some cases radiation may play a part in producing these, but it is often difficult to assess whether the tumour, the surgery, or the irradiation has been the major cause of the damage. Many of the nerve effects are due to tumour and were present before treatment began, but it is impossible to measure the effects of either tumour or treatment on such things as intellect, as we have no certain guide as to how a particular child might have developed.

In this paper an attempt has been made to assess $\overrightarrow{\vec{F}}$ the value of irradiation in the treatment of tumours in children. With some of the neoplasms, radiotherapy has an established place and it and is necessary to assess the radiosensitivity of the rarer tumours. $\mathbb{\nabla}$ In the future we must try to discover why some children's neoplasms are radioresistant and whether's results might be improved by a combination of $\vec{O}$ surgery, irradiation, and chemotherapy.

REFERENCE

Stallard, H. B. (1955). Ann. roy. Coll. Surg. Engl., 16, 349. 